\title{
Urban and rural income, residents' consumption structure and energy consumption
}

\author{
Yan $\mathrm{Li}^{1}$, Zhi-wei Liu ${ }^{1}$, Nan-nan $\mathrm{Li}^{1}$, Jia-li Zhang ${ }^{1}$, Ya-chen Wang ${ }^{1}$, Zhuo-wen Zuo ${ }^{1}$, Xiang-yu Zhang ${ }^{1}$ \\ ${ }^{1}$ State Grid Shanxi Economic research Institute, Taiyuan, Shanxi, 030002, China)
}

\begin{abstract}
As an internal driving force to promote economic growth, residents' consumption also has an important impact on energy consumption. Based on the difference of consumption structure between urban and rural residents, this paper introduces the income gap variable of urban and rural residents, analyzes the impact of urban and rural residents' consumption on energy consumption, and provides reference for the implementation of energy conservation and emission reduction policies. On this basis, the author believes that the government should take flexible measures to control energy consumption according to the differences between urban and rural areas, make accurate efforts, and steadily promote the implementation of energy conservation and emission reduction.
\end{abstract}

\section{Introduction}

The report of the 19th National Congress of the Communist Party of China clearly put forward the overall layout of "five in one", pointing out that China's economy has changed from the stage of high-speed growth to the stage of high-quality development, and is in the crucial period of transforming the mode of development, optimizing the industrial structure and transforming the driving force of growth. Under the new situation, the work of energy conservation and emission reduction is steadily and orderly promoted. Energy as the theme of energy conservation work, the analysis of the factors affecting energy consumption has important practical significance for the implementation of energy conservation and emission reduction.

The existing studies believe that there is a close relationship between household consumption and energy consumption. The energy consumption caused by residents' daily consumption expenditure accounts for $45 \%$ - $50 \%$ of the total energy consumption[1]. Residents' consumption has become the main factor leading to the increase of energy consumption[2][3]. Considering the imbalance of regional economic development in China, Qin Teng and others used the provincial panel data from 1990 to 2013 to conduct regression analysis on the relationship between residents' consumption and energy consumption in the whole country, the East, the west, the West and the East. The results show that there is a significant nonlinear relationship between household consumption and energy consumption at the national level. In the relatively developed eastern region, residents' consumption ability is strong, and the promotion effect of residents' consumption on energy consumption is the most significant. However, with the improvement of residents' income level, the correlation coefficient will continue to decrease. On the contrary, the promotion effect of residents' consumption on energy consumption in the western region is gradually enhanced with the increase of residents' income[4].

At present, China's economic development is not only unbalanced in the East, the middle and the west, but also a problem worthy of attention. It is also found that the widening income gap between urban and rural areas will reduce the energy efficiency of the whole society. Under the income gap between urban and rural areas, Reinders analyzed the energy consumption data of European countries and concluded that the total energy consumption caused by different consumption levels was different, and the difference of urban and rural residents' consumption level led to the heterogeneity of urban and rural energy consumption structure[5]. Chen Xun and Yuan Haiwei (2008) used cointegration analysis method to verify that the actual consumption expenditure factor is the main influencing factor of China's domestic energy demand, and believe that the urbanization process and the change of energy consumption structure have little impact on domestic energy consumption[6]. Chen Xihong and others used the provincial panel data from 1985 to 2008 to make an empirical analysis, which shows that the widening of urban-rural income gap is not conducive to the improvement of social energy efficiency[7]. The existing research shows that it is of practical significance to analyze the energy consumption of residents from the perspective of income and consumption.

Due to the unbalanced development of urban and rural areas, there is a big gap in residents' consumption behavior. In recent ten years, the per capita income ratio of urban and rural residents has always been greater than 2.7 , and the ratio of urban and rural consumption level has always been greater than 2 . In recent years, the scale of residents' 
consumption expenditure has been increasing year by year, at the same time, the demand of consumption has become increasingly diverse. The proportion of basic consumption such as food and clothing commodities used to meet the basic living needs in the total consumption expenditure has gradually decreased, while the proportion of development and enjoyment consumption such as transportation and communication, entertainment and tourism, medical care and so on has gradually increased. The change of consumption structure is bound to have a certain impact on energy consumption. To sum up, the existing domestic empirical studies only focus on the differences of regional economic development in China, and few articles analyze it from the perspective of urbanrural development differences. In addition, most of the existing domestic related studies take the level of residents' consumption as the main explanatory variable, and the data used are before 2013, which is relatively old. The research on the change of residents' consumption structure on energy consumption is also less. This paper creatively takes urban and rural areas as two research subjects. The time span is from 2007 to 2017 before and after the implementation of the energy revolution. Based on the background of urban-rural dual development in China, the per capita income of residents is taken as the threshold variable to explore the impact of the upgrading of consumption structure of urban and rural residents on energy consumption under the corresponding threshold Targeted guidance of urban and rural residents consumption, to reduce energy consumption to provide theoretical basis and policy recommendations.

\section{Research design}

\subsection{Variable selection and data source}

The explained variable in this paper is energy consumption, which is measured by ten thousand tons standard coal consumption data at the end of each region. Meanwhile, in order to avoid the negative impact of heteroscedasticity, the logarithm is selected in the research and analysis. This paper selects the consumption upgrading index of urban residents and the consumption upgrading index of rural residents as the main explanatory variables of this paper. Learning from the existing research of domestic scholars[8], The consumption upgrading index of urban residents is determined by the proportion of the sum of the consumption of medical care, education and culture, transportation and communication in the total consumption of urban residents in each province. The consumption upgrading index of rural residents is calculated by the same method. The per capita income of urban residents and rural residents is the threshold variable of this paper. In order to eliminate the influence of price factors, the data are converted based on 1978. Research shows that technological progress can effectively restrain energy consumption in China[9], The level of regional economic development and population size are the important driving factors to stimulate the growth of energy consumption[10], However, the industrial structure has a nonlinear effect on energy consumption, and there is an obvious threshold effect between the upgrading of industrial structure and energy consumption[11]. In order to control the impact of the above variables on energy consumption, this paper takes them as control variables into the model. Referring to the existing research, this paper uses the percentage of regional invention patent granted in the total number of patent granted to measure the level of regional technological progress; GDP is used to measure the level of regional economic development, which is also converted based on 1978; meanwhile, in order to eliminate the influence of heteroscedasticity on the accuracy of estimation results, logarithmic processing is carried out; the total population at the end of each region is used to measure the regional level of technological progress The population size of the district is also treated by logarithm, and the industrial structure is measured by the ratio of the output value of the secondary industry and the tertiary industry.

The data in this paper are all from "China Energy Statistical Yearbook" and "China Statistical Yearbook". The time span is from 2007 to 2017. In order to ensure the integrity of the data, Tibet and Xinjiang are excluded from the research object. The descriptive statistics of each variable are shown in Table 1.

\begin{tabular}{|c|c|c|c|c|c|c|}
\hline Variable name & Variable code & $\begin{array}{l}\text { Number of } \\
\text { samples }\end{array}$ & Mean & $\begin{array}{l}\text { standard } \\
\text { deviation }\end{array}$ & $\begin{array}{l}\text { minimum } \\
\text { value }\end{array}$ & Maximum \\
\hline $\begin{array}{l}\text { Total energy consumption ( } 10000 \\
\text { tons of standard coal) }\end{array}$ & energy & 319 & 13162.04 & 8210.48 & 920 & 38899 \\
\hline $\begin{array}{l}\text { Consumption upgrading index of } \\
\text { urban residents }\end{array}$ & City_cos & 319 & 0.32 & 0.03 & 0.26 & 0.41 \\
\hline $\begin{array}{l}\text { Consumption upgrading index of } \\
\text { rural residents }\end{array}$ & Rural_cos & 319 & 0.29 & 0.07 & 0.21 & 0.32 \\
\hline $\begin{array}{l}\text { Per-capita income of urban } \\
\text { residents (yuan) }\end{array}$ & City_income & 319 & 21412.53 & 8865.47 & 8921 & 57692 \\
\hline $\begin{array}{l}\text { Per-capita income of rural } \\
\text { residents (yuan) }\end{array}$ & Rural_income & 319 & 8036.06 & 4340.18 & 1985 & 25520 \\
\hline $\begin{array}{l}\text { Regional technological progress } \\
\text { level }\end{array}$ & tech & 319 & 0.47 & 0.81 & 0.19 & 0.61 \\
\hline Population size (10000) & people & 319 & 4529.95 & 2682.71 & 548 & 10999 \\
\hline $\begin{array}{l}\text { GDP ( } 100 \text { million yuan) } \\
\text { industrial structure }\end{array}$ & $\begin{array}{l}\text { Gdp } \\
\text { industry }\end{array}$ & $\begin{array}{l}319 \\
319\end{array}$ & $\begin{array}{l}4095.13 \\
1.17\end{array}$ & $\begin{array}{l}3845.06 \\
0.30\end{array}$ & $\begin{array}{l}144.32 \\
0.42\end{array}$ & $\begin{array}{l}23379.67 \\
2.05\end{array}$ \\
\hline
\end{tabular}




\subsection{Model setting}

In order to better explain the relationship between urban and rural residents' consumption upgrading and energy consumption, this paper takes the per capita income of urban and rural residents as the threshold variable and adopts the threshold model of nonlinear relationship between explanatory variables to measure the critical value of urban and rural residents' consumption upgrading and energy consumption. Firstly, the regression equations of single threshold and double threshold are set as follows:

$$
\mathrm{y}_{i t}=\beta_{0+} \beta_{1} Z_{i t}+\theta_{1} X_{i t} I\left(q_{i t} \leq r_{1}\right)+\theta_{2} X_{i t} I\left(q_{i t}>r_{1}\right)+u_{i t}+\varepsilon_{i t}
$$

$y_{i t}=\beta_{0+} \beta_{1} Z_{i t}+\theta_{1} X_{i t} I\left(q_{i t} \leq r_{1}\right)+\theta_{2} X_{i i} I\left(r_{1}<q_{i t} \leq r_{2}\right)+\theta_{3} X_{i t} I\left(q_{i t}>r_{2}\right)+u_{i t}+\varepsilon_{i t}$

In the above formula $\mathrm{y}$ is the energy consumption intensity, $\mathrm{Z}$ is the set of control variables, and $\mathrm{X}$ is the upgrading index of consumption structure of urban and rural residents. $q$ is the threshold variable expressed by the per capita income of urban and rural residents. $\beta 0, \beta 1, \theta$ $1, \theta 2$ are the output elasticity coefficients of each variable, uit are regional fixed effects and cit is the random interference term. $r$ is the threshold value to be estimated, $\mathrm{i}$ and $\mathrm{t}$ represent provinces and years respectively. $\mathrm{I}(\bullet)$ is an explicit function. When the condition of the function is satisfied, the value is 1 . Otherwise, the value is 0 .

This paper uses the above model to study the threshold effect of consumption upgrading. The steps are divided into three steps: (1) to test the threshold effect of per capita income of urban and rural areas to determine whether it is a single threshold model or a multi threshold model; (2) to determine the threshold value of per capita income and its confidence interval, and draw the likelihood ratio (LR) diagram of the threshold value; (3) to test the threshold effect of consumption upgrading in urban and rural areas The threshold value of urban and rural residents is brought into the threshold regression model, and the threshold regression results are calculated and the significance test is carried out, so as to obtain the impact of residents' consumption upgrading on energy consumption under different income levels of urban and rural residents. Finally, through the research results, find the rational balance point between energy conservation and emission reduction and residents' consumption, and further reduce social energy consumption by guiding residents' consumption.

\section{Empirical analysis}

\subsection{The threshold effect of household consumption upgrading on energy consumption}

Using stata14.0 software, taking the per capita income of rural residents and the per capita income of urban residents as threshold variables, the following conclusions are obtained through the test: (1) there is a double threshold of per capita income between rural residents' consumption upgrading index and energy consumption. The first threshold was 7.1 and the second threshold was 8.5. (2)
There is a double threshold of per capita income between the consumption upgrading index of urban residents and energy consumption. The first threshold was 8.97 and the second threshold was 11.51 .

\subsection{Regression results of threshold model}

When the per capita income of urban residents is less than the minimum threshold value, the influence coefficient of consumption structure upgrading on energy consumption is -0.49 at the significance level of $5 \%$. When the per capita income is in the middle range, the coefficient decreases to -0.29 , but it is still significant at the level of $10 \%$. With the per capita income level of urban residents crossing the highest threshold and at the highest level, the consumption upgrading of urban residents has the greatest inhibitory effect on energy consumption, and the correlation coefficient is -0.80 , which is significant at the level of $1 \%$. The inhibition effect of urban residents' consumption upgrading on energy consumption decreases first and then increases with the increase of per capita income level. Generally speaking, the upgrading of consumption structure of urban residents in the region will inhibit regional energy consumption.

Correspondingly, when the per capita income of rural residents is in the minimum range, the consumption structure of rural residents has no significant impact on energy consumption. When the per capita income of rural residents crosses the minimum threshold and is in the middle level, the impact coefficient of rural residents' consumption upgrading index on energy consumption is 0.11 , which is significant at the level of $5 \%$. When the per capita income of rural residents crosses the highest threshold, the promotion effect is further strengthened. The negative coefficient of rural residents' consumption upgrading on energy consumption increases to - 0.197 , which is significant at the level of $10 \%$. In the rural areas with low income level, the increase of income will not affect the consumption structure of residents, and the consumption of residents is still based on the basic living needs. After crossing the minimum threshold, the inhibition effect of rural residents' consumption upgrading on energy consumption increases with the increase of per capita income level.

\section{Policy suggestion}

This paper puts forward the following suggestions: when formulating corresponding policies, the government should combine the differences between urban and rural areas and adjust measures to local conditions. The government should strengthen the transformation of urban residents' living consumption and transportation towards low-carbon lifestyle, make full use of the advantages of human capital in urban areas, strengthen $R \& D$ investment, encourage scientific and technological innovation, and realize the saving of production factors through technological progress. On this basis, the government should give appropriate policy preference to the field of new energy and energy-saving and environmental protection products, and encourage urban 
residents to become knowledge intensive The consumption transformation of type industry and service industry. In rural areas, we should give corresponding subsidies to eliminate high energy consumption household equipment in rural areas, and promote energy-saving household appliances at low cost. We will adjust and optimize the energy structure and increase the proportion of high-quality energy and alternative energy.

\section{References}

1. Schipper L, Bartlett, et al. Linking life-styles and energy use:a matter of Time[M]. Annual Review of Energy,1989,14.

2. Park H C, Heo E. The direct and indirect household energy requirements in the Republic of Korea from 1980 to 2000 - An input-output analysis[J].Energy Policy.2007(35):2839-2851.

3. Li Y. A test of the dynamic influence of household consumption on energy consumption[J]. Business economy research,2015(12):54-56.

4. Qing T, Zhang H Q and Tong J P. Analysis on the impact of residents' consumption on energy consumption considering regional differences: An Empirical Study Based on threshold model[J]. soft science, 2016, 30(5):96-99.

5. Reinders $\mathrm{A}$, Vringer $\mathrm{K}$, and Blok $\mathrm{K}$. The direct and indirect energy requirements of households in the european union[J].Energy Policy,2003,31(2):139-153.

6. Chen X, Yuan H W. Empirical Study on Influencing Factors of domestic energy consumption behavior in China[J]. Consumption economy, 2008(05):47-50.

7. Chen X H, Li C Q, Zhang G R, et al. Analysis of the impact of income gap on energy efficiency in the process of Urbanization[J]. inquiry into economic issues, 2011(7):144-149.

8. Huang J, Li J K. The characteristics, measurement and development of China's consumption upgrading[J]. China's circulation economy, 2018(4): 94-101.

9. Han S, Zhang B S , Tang X, et al. Analysis on driving factors of China's energy intensity change -- Based on logarithmic average Dirichlet index method[J]. Contemporary economic science, 2016,38(05):89-98.

10. Yang H J, Liu H Y and Liu H Q. Analysis of influencing factors of energy consumption in Yunnan Minority Areas Based on LMDI model[J]. Journal of Kunming University of science and technology: Social Science Edition,2015(15):58.

11. Chen H B, Chai H X and Xin L.Nonlinear effects of industrial structure upgrading on energy consumption [J]. Statistics and decision making,2019(13):144-146. 